\title{
PENGARUH KEPRIBADIAN DAN KOMUNIKASI INTERPERSONAL TERHADAP KOMITMEN ORGANISASIONAL PADA DINAS KESEHATAN KOTA PALOPO
}

\author{
Nur Laela Sayuti ${ }^{1}$, Sirajuddin Sammang ${ }^{2}$ \\ Email : nurlaelasayuti@gmail.com
}

Akademi Manajemen Informatika dan Komputer (AMIK) Ibnu Khaldun Palopo

\begin{abstract}
Abstrak
Salah satu sumber daya organisasi yang memiliki peran penting dalam mencapai tujuannya adalah sumber daya manusia baik itu pada sektor swasta maupun sektor publik. Keadaan ini menjadikan sumber daya manusia sebagai aset yang harus ditingkatkan efisiensi dan produktivitasnya. Penelitian ini bertujuan untuk : 1) Mengetahui seberapa besar pengaruh variabel-variabel kepribadian (Neuroticism, Extraversion, Openness to Experience, Agreeableness, Conscientiousness) dan komunikasi interpersonal memberi pengaruh terhadap komitmen organisasional pada kantor Dinas Kesehatan Kota Palopo. 2) Mengetahui, di antara variabel Neuroticism, Extraversion, Openness to Experience, Agreeableness, Conscientiousness, dan komunikasi interpersonal, variabel manakah yang dominan yang mempengaruhi komitmen Organisasional pada kantor Dinas Kesehatan Kota Palopo. Metode analisis yang digunakan adalah metode analisis linear berganda yang didukung pula dengan analisis deskrptif. Hasil penelitian menunjukkan bahwa : 1) terdapat pengaruh positif dan signifikan antara variabel kepribadian (Neuroticism, Extraversion, Openness to Experience, Agreeableness, Conscientiousness) dan komunikasi interpersonal terhadap komitmen organisasional pada kantor Dinas Kesehatan Kota Palopo. 2) Variabel yang paling dominan memberi pengaruh terhadap komitmen organisasional pada Dinas Kesehatan Kota Palopo adalah variabel Conscientiousness. 3) Hasil Uji Koefisien Determinasi (R2) dengan nilai R2 sebesar 0.735, ini menunjukkan bahwa variabel independent adalah variabel yang mempengaruhi variabel dependent sebesar $73.5 \%$. Sementara $26.5 \%$ dari variabel Dependent dipengaruhi oleh lainnya yang tidak termasuk dalam variabel penelitian. 4) Hasil uji serempak dan uji parsial menjelaskan bahwa baik secara bersama-sama maupun secara parsial semua variabel Independent mempengaruhi variabel Dependent.
\end{abstract}

Kata Kunci: Variabel Kepribadian, Komitmen Organisasional

\section{PENDAHULUAN}

Komunikasi merupakan salah satu hal yang penting diperhatikan dalam mencapai dan mengembangnkan tujuan yang akan dicapai dalam sebuah organisasi di sebuah instansi.Salah satu sumber daya organisasi yang memiliki peran penting dalam mencapai tujuannya adalah sumber daya manusia baik itu pada sektor swasta maupun sektor publik. Keadaan ini menjadikan sumber daya manusia sebagai aset yang harus ditingkatkan efisiensi dan produktivitasnya. Untuk mencapai hal tersebut, maka perusahaan harus mampu menciptakan kondisi yang dapat mendorong dan memungkinkan karyawan untuk mengembangkan dan meningkatkan kemampuan serta keterampilan yang dimiliki secara optimal. Karyawan yang bekerja dalam sebuah organisasi sebaiknya diperlakukan sebaik-baiknya, agar karyawan mempunyai kinerja yang baik dan tujuan organisasi dapat tercapai.
Manajer atau pimpinan seharusnya juga mengetahui kemampuan yang dimiliki karyawan dan kebutuhankebutuhan yang diperlukan sebagai pendukung dalam bekerja sehingga kinerja karyawan bagus dan pekerjaan dapat diselesaikan lebih efektif dan efisien, (Alwisol. 2005).

Organisasi harus mempunyai komunikasi yang efektif demi pencapaian tujuan. Setiap karyawan harus mempunyai komunikasi efektif dalam kesehariannya menjalankan tugas. Komunikasi tidak efektif akan memberikan dampak negatif pada organisasi, khususnya komunikasi interpersonal yang memberikan kontribusi terhadap besarnya tingkat komitmen seorang karyawan pada organisasinya. Komunikasi interpersonal yang mampu terjalin dengan baik akan memubuhkan rasa emosionalitas (kekeluargaan) sesama karyawan sehingga rasa saling memiliki dalam sebuah organisasi itu semakin besar (Ardana, dkk, 2012). Namun jika komunikasi itu 
tidak berjalan secara efektif justru akan menimbulkan pertengkaran, saling iri, saling menjatuhkan dan dampak negatif lainnya (Bangun, 2012). Seperti yang terjadi pada salah satu instansi pemerintah, komunikasi interpersonal tidak terjadi secara efektif mengakibatkan perselisihan berkelanjutan sesama karyawan, saling tuding sehingga tercipta lingkungan kerja yang tidak nyaman. Lingkungan kerja yang tidak nyaman mengakibatkan rendahnya komitmen organisasi sehingga beberapa karyawan mengharapkan pemindahan (mutasi) (Budyatna dkk, 2011).

Setiap karyawan pada sebuah organisasi memiliki tanggung jawab yang berbeda-beda. Seorang manajer harus mampu memberikan pekerjaan yang sesuai dengan keahlian setiap individu, pemberian pekerjaan yang tidak sesuai dengan keahlian karyawan akan memberikan dampak negatif kepada organisasi (Dessler, 2010). Ketidakpahaman seorang karyawan akan tugas yang diberikan akan membuat tugas tersebut terbengkalai atau mungkin saja terselesaiakan tetapi tidak efektif dan efisien. Namun, seorang karyawan bisa saja menempati posisi yang tidak sesuai dengan keahliannya dengan syarat diberikan pelatihan dan bimbingan yang mungkin cukup lama dan memakan biaya (Iriantara, 2008). Selain itu, manajer juga harus membuat dan memberikan job description yang jelas kepada setiap karyawan agar tidak terjadi penumpukan beban kerja pada satu karyawan saja. Pemberian job description juga memperlihatkan tanggung jawab dari masing-masing karyawan, selanjutnya hal ini akan memberi pengaruh terhadap besarnya komitmen seorang karyawan pada organisasinya (Ivancevich dkk, 2007).

Gordon W Alport yang menyatakan bahwa kepribadian itu adalah organisasi dinamis dalam diri individu sebagai system psiko-fisik yang menentukan caranya yang uunik dalam menyesuaikan diri terhadap lingkungannya. Teori Model Lima Besar Kepribadian dan Komponen dari Model Lima Besar yang dikembangkan oleh Costa dan Mc Grae. Teori komunikasi interpersonal yang dikemukakan oleh Tubs \& Moss yang mengatakan bahwa komunikasi interpersonal bersifat diadik, mencakup semua jenis hubungan manusia mulai dari hubungan yang paling singkat dan biasa yang seringkali diwarnai oleh kesan pertama, hingga hubungan yang paling mendalam dan langgeng. Teori komitmen organisasi yang dikemukakan oleh Allen \& Mayer yang merefleksikan komitmen organisasi kedalam tiga komponen yaitu Affective Commitment, Continuance Commitment, dan Normative Commitment, faktor-faktor komitmen organisasi.

Penelitian ini bertujuan untuk Mengetahui seberapa besar pengaruh variabel-variabel kepribadian terhadap komitmen organisasional pada kantor Dinas Kesehatan Kota Palopo.

\section{METODE PENELITIAN}

\section{Rancangan Penelitian}

Pada penelitian ini memiliki tujuan yakni untuk mengetahui pengaruh kepribadian karyawan dan komunikasi interpersonal antar pegawai terhadap komitmen organisasi pada kantor Dinas Kesehatan Kota Palopo. Metode penelitian yang digunakan adalah penelitian korelasional yang bermaksud mendeteksi sejauh mana variasi-variasi pada komponen-komponen kepribadian dan komunikasi interpersonal sebagai variabel independen terhadap komitmen organisasional sebagai variabel dependen.

\section{Populasi dan Sampel}

Adapun populasi pada penelitian ini adalah daerah generalisasi yang terdiri atas : objek/subjek yang mempunyai kualitas dan karakteristik tertentu yang ditetapkan oleh peneliti untuk dipelajari dan kemudian ditarik kesimpulannya (Sugiyono, 2012). Populasi pada penelitian ini adalah seluruh karyawan Dinas Kesehatan Kota Palopo Sebanyak 312 orang, tetapi pada penelitian ini hanya mengambil sebagian dari karyawan dinas kesehatan kota palopo yakni 206 orang saja.

Apa yang dipelajari dari sampel itu, kesimpulannya akan dapat diberlakukan untuk populasi. Untuk itu, sampel yang di ambil dari populasi harus betul-betul representatif (mewakili). Pada penelitian ini, peneliti menentukan jumlah sampel dengan menggunakan Rumus Slovin sebagai berikut :

$$
n=\frac{N}{1+n e^{2}}
$$

206

$1+206(0,01)^{2}$

201,842 dibulatkan menjadi 202 dimana

$\mathrm{n}$ : jumlah sampel

$\mathrm{N}$ : jumlah populasi

e : batas toleransi kesalahan

(errortolerance)

\section{Teknik Pengumpulan Data}

Untuk lebih akuratnya data yang diperlukan dalam penelitian ini maka penulis menggunakan metode Teknik pengamatan langsung (field research) yaitu metode pengumpulan data melalui observasi lapangan atau objek penelitian dan pembagian kuisioner kepada setiap karyawan, dan Metode Library Research, yaitu metode pengumpulan data berupa data-data sekunder yang dapat diperoleh oleh penulis dengan mereview buku-buku, beberapa jurnal penelitian sebelumnya dan berbagai artikel-artikel untuk menunjang kajian hasil penelitian dan dapat membantu dalam perumusan instrumen pada penelitian ini.

\section{Teknik Analisis Data}

Penelitian ini mengumpulkan beberapa data-data primer kemudian setelah itu peneliti kumpulkan pula beberapa data-data penunjang lainnya yang diperoleh dari 
instansi terkait dengan komponen kerja perusahaan, maka dilakukan input dan editing data yang berupa kuesioner. Data lalu kemudian diinput dan dianalisis berikut metode skoring kuesioner yang digunakan untuk kemudian menjadi item-item variabel yang dapat dianalisis secara statistik.

Analisis statistik yang digunakan dalam penelitian ini adalah analisis regresi linear ganda dengan menggunakan program statistik SPSS. Analisis regresi linear ganda digunakan untuk menghitung besarnya pengaruh secara kuantitatif dari suatu perubahan kejadian beberapa variabel X secara bersamaan terhadap kejadian variabel Y. Dalam penelitian ini analisis regresi linear ganda berperan sebagai teknik statistik yang digunakan untuk mengukur ada tidaknya pengaruh kepribadian karyawan dan komunikasi interpersonal terhadap komitmen organisasi pada Dinas Kesehatan Kota Palopo.

\section{HASIL}

Tabel 1. Hasil Regresi

\begin{tabular}{|c|c|c|c|c|}
\hline \multicolumn{5}{|c|}{ Coefficients $^{\mathbf{a}}$} \\
\hline \multirow{4}{*}{ Model } & \multicolumn{2}{|c|}{ Unstandardized } & \multicolumn{2}{|l|}{ Standardized } \\
\hline & \multicolumn{2}{|c|}{ Coefficients } & \multicolumn{2}{|l|}{ Coefficients } \\
\hline & B & Std. & Beta & Sig. \\
\hline & & Error & & \\
\hline (Constant) & 3.596 & 3.847 & & 0.018 \\
\hline $\mathrm{X}_{1}$ & 0.046 & 0.080 & 0.040 & 0,005 \\
\hline $\mathrm{X}_{2}$ & 0.051 & 0.093 & 0.053 & 0.006 \\
\hline $\mathrm{X}_{3}$ & 0.055 & 0.062 & 0.028 & 0.000 \\
\hline $\mathrm{X}_{4}$ & 0.032 & 0.093 & 0.032 & 0.001 \\
\hline $\mathrm{X}_{5}$ & 0.043 & 0.072 & 0.044 & 0.002 \\
\hline $\mathrm{X}_{6}$ & 0.045 & 0.068 & 0.046 & 0.003 \\
\hline
\end{tabular}

a. Dependent Variable: y

Sumber : data diolah 2013

Dari tabel 1 terlihat bahwa, akan diperoleh persamaan regresi linear berganda yaitu $\mathrm{Y}=3,596+0,046 \mathrm{X} 1+$ $0,051 \mathrm{X} 2+0,055 \mathrm{X} 3+0,032 \mathrm{X} 4+0,043 \mathrm{X} 5+0,045 \mathrm{X} 6$ $+2,528$ a= 3,596; artinya apabila X1, X2, X3, X4, X5, $\mathrm{X} 6=0$, maka nilai $\mathrm{Y}=3,596 . \mathrm{b} 1=0,046$; artinya apabila kenaikan X2, X3 , X4, X5, X6 konstan, maka kenaikan $\mathrm{X} 1$ sebesar 1 satuan akan menyebabkan kenaikan $\mathrm{Y}$ sebesar 0,046. b2 =0,051; artinya apabila kenaikan X1, X3 , X4, X5, X6 konstan, maka kenaikan X2 sebesar 1 satuan akan menyebabkan kenaikan Y sebesar 0,051. b3 $=0,055$ artinya apabila kenaikan X1, dan X2 X4 X5 X6 konstan, maka kenaikan X3 sebesar 1 satuan akan menyebabkan kenaikan $\mathrm{Y}$ sebesar 0,055. b4 =0,032 artinya apabila kenaikan X1, X2, X3, X5, X6 konstan, maka kenaikan X4 sebesar 1 satuan akan menyebabkan kenaikan $\mathrm{Y}$ sebesar 0,032. b5 = 0,043 artinya apabila kenaikan X1, X2, X3, X4, X6 konstan, maka kenaikan X5 sebesar 1 satuan akan menyebabkan kenaikan Y sebesar 0,043. b6 $=0,045$ artinya apabila kenaikan $\mathrm{X} 1$, X2, X3, X4, X5 konstan, maka kenaikan X6 sebesar 1 satuan akan menyebabkan kenaikan Y sebesar 0,045.

Koefisien determinasi pada intinya mengukur seberapa jauh kemampuan model dalam menerangkan variasi variabel terikat. Nilai koefisien determinasi berkisar dari 0-1 (0\%-100\%). Semakin mendekati nilai 0 maka variabel bebas dianggap hanya memiliki pengaruh simultan yang kecil terhadap variabel terikat, sedangkan semakin mendekati nilai 1 maka variabel bebas dianggap memiliki pengaruh yang besar terhadap variabel terikat. 
Tabel 2. Hasil Uji Koefisien Determinasi $\left(\mathbf{R}^{\mathbf{2}}\right)$

\begin{tabular}{|c|c|c|c|c|}
\hline \multicolumn{5}{|c|}{ Model Summary ${ }^{b}$} \\
\hline Model & $\mathrm{R}$ & R Square & Adjusted R Square & Std. Error of the Estimate \\
\hline 1 & $.885^{\mathrm{a}}$ & .735 & .727 & 2.528 \\
\hline \multicolumn{5}{|c|}{ a. Predictors: (Constant), x6, x1, x2, x5, x3, x4 } \\
\hline b. Dep & & & & \\
\hline
\end{tabular}

Sumber : data diolah, 2013

Berdasarkan tabel 2 dilihat pengaruh variabel bebas terhadap variabel terikat menghasilkan nilai koefisien korelasi (R) sebesar 0,885 berarti seluruh variabel bebas (X1, X2, X3, X4, X5, dan X6,) dalam penelitian ini mempunyai hubungan positif dan kuat terhadap variabel terikat (Y) sebesar $88,5 \%$, sisanya sebesar $11,5 \%$ dipengaruhi oleh faktor-faktor lain. Sedangkan koefisien determinasi (R2) sebesar 0,735 berarti seluruh variabel bebas (X1, X2, X3, X4, X5, dan X6,) dalam penelitian ini mempunyai kontibusi secara bersama-sama sebesar 73,5\% terhadap variabel terikatnya yakni komitmen (Y).

Tabel 3. Hasil Uji F

\begin{tabular}{|c|c|c|c|c|c|}
\hline \multicolumn{6}{|c|}{ ANOVA $^{a}$} \\
\hline Model & Sum of Squares & df & Mean Square & $F_{\text {hitung }}$ & Sig. \\
\hline Regression & 232.316 & 6 & 38.719 & 6.057 & $.000^{\mathrm{b}}$ \\
\hline Residual & 754.276 & 118 & 6.392 & & \\
\hline Total & 986.592 & 124 & & & \\
\hline \multicolumn{6}{|c|}{ a. Dependent Variable: y } \\
\hline b. Predictors & $\mathrm{x} 2, \mathrm{x} 5, \mathrm{x} 3, \mathrm{x} 4$ & & & & \\
\hline
\end{tabular}

Sumber : data diolah, 2013

Berdasarkan tabel 3 dilihat bahwa hitung sebesar 6,057, sedangkan nilai Ftabel distribusi dengan tingkat kesalahan 5\% adalah sebesar 2,18. Hal ini berarti Fhitung $>$ Ftabel $(6,057>2,18)$. Perhitungan tersebut menunjukkan bahwa variabel bebas (X1, X2, X3, X4, $\mathrm{X} 5$, dan X6,) secara bersama mempunyai pengaruh yang positif dan signifikan terhadap variabel terikat (Y).

Variabel X1 (Extraversion), Nilai thitung untuk variabel ini sebesar 2,584 dengan signifikansi 0,000. Nilai tabel untuk model regresi diatas adalah 1,98027. Hasil uji tersebut menunjukkan bahwa nilai signifikansi $(0,000)<$ nilai $\alpha 5 \%(0,05)$ dan nilai thitung $(2,548)>$ ttabel $(1,98027)$.

Variabel X2 (Agreeableness), Nilai thitung untuk variabel ini sebesar 2,645 dengan signifikansi 0,005 . Nilai tabel untuk model regresi diatas adalah 1,98027. Hasil uji tersebut menunjukkan bahwa nilai signifikansi $(0,005)<$ nilai $\alpha 5 \%(0,05)$ dan nilai thitung $(2,645)>$ ttabel $(1,98027)$.
Variabel X3 (Conscientiousness), Nilai thitung untuk variabel ini sebesar 3,764 dengan signifikansi 0,006. Nilai tabel untuk model regresi diatas adalah 1,98027. Hasil uji tersebut menunjukkan bahwa nilai signifikansi $(0,006)<$ nilai $\alpha 5 \%(0,05)$ dan nilai thitung $(3,764)>$ ttabel $(1,98027)$.

Variabel X4 (Neuroticism), Nilai thitung untuk variabel ini sebesar 3,473 dengan signifikansi 0,001. Nilai tabel untuk model regresi diatas adalah 1,98027. Hasil uji tersebut menunjukkan bahwa nilai signifikansi $(0,001)<$ nilai $\alpha 5 \%(0,05)$ dan nilai thitung $(3,473)>$ ttabel $(1,98027)$.

Variabel X5 (Openness To Experience), Nilai thitung untuk variabel ini sebesar 3,564 dengan signifikansi 0,002. Nilai tabel untuk model regresi diatas adalah 1,98027. Hasil uji tersebut menunjukkan bahwa nilai signifikansi $(0,002)<$ nilai $\alpha 5 \%(0,05)$ dan nilai thitung $(3,564)>$ ttabel $(1,98027)$.

Variabel X6 (Interpersonal Communication), Nilai thitung untuk variabel ini sebesar 2,581 dengan 
signifikansi 0,003 . Nilai tabel untuk model regresi diatas adalah 1,98027. Hasil uji tersebut menunjukkan bahwa nilai signifikansi $(0,002)<$ nilai $\alpha 5 \%(0,05)$ dan nilai thitung $(2,581)>$ ttabel $(1,98027)$.

\section{PEMBAHASAN}

Pada penelitian ini terlihat bahwa variabel yang paling dominan mempengaruhi Komitmen Organisasi (Y) adalah variabel Conscientiousness (X3) dengan nilai terhitung yang paling besar $(3,764)$. Dengan demikian hipotesis pada penelitian ini yang menyatakan dugaan bahwa variabel Conscientiousness (X3) merupakan variabel yang paling dominan berpengaruh terhadap komitmen organisasi (Y) terbukti dan dapat diterima.

Uji normalitas data digunakan untuk mengetahui normal tidaknya masing-masing variabel penelitian. Dalam penelitian ini uji normalitas dilakukan dengan uji One Sample Kolmogorof-Smirnov dengan menggunakan taraf signifikansi 0,05. Data dinyatakan berdistribusi normal jika signifikansi lebih besar dari 0,05 atau 5\%.

Uji linieritas bertujuan untuk mengetahui apakah dua variabel mempunyai hubungan yang linier atau tidak secara signifikan. Pengujian pada SPSS dengan menggunakan Test For Linieritas pada taraf signifikan 0,05. Dua variabel dikatakan mempunyai hubungan yang linier bila signifikan kurang dari 0,05. pengolahan data untuk uji linearitas dengan menggunakan Software SPSS 21, maka diperoleh hasil sig dari pengolahan data antara variabel terikat terhadap masing-masing variabel bebas nya lebih kecil dibanding 0,05. Hal ini membuktikan bahwasanya variabel terikat dalam penelitian ini, yaitu komitmen organisasi memiliki hubungan yang linear terhadap masing-masing variabel bebasnya.

Uji Multikoliniearitas dilakukan untuk menghindari kebiasan dalam proses keputusan mengenai pengaruh parsial atau terpisah dari masing-masing variabel bebas terhadap variabel terikat. Syarat berlakunya model regresi berganda adalah variabel bebas tidak memiliki hubungan sempurna atau mengandung multikoliniearitas terhadap variabel terikatnya. Deteksi terhadap ada atau tidaknya multikoliniearitas adalah dengan melihat nilai Variance Inflation Factor (VIF) pada model regresi dan membandingkan besarnya terhadap nilai tolerance.

Uji heteroskedastisitas bertujuan untuk mengetahui apakah terjadi ketidaksamaan varians dari residual untuk semua pengamatan dalam model regresi. Prasyarat yang harus terpenuhi dalam model regresi adalah tidak adanya gejala heteroskedastisitas. Untuk mengetahui gejala heteroskedastisitas dapat dilakukan dengan mengamati scatterplot model tersebut. Model yang bebas dari heteroskedastisitas memiliki grafik scatterplot dengan pola titik yang menyebar di atas dan di bawah sumbu Y.

\section{KESIMPULAN DAN SARAN}

Variabel Extraversi (X1) memiliki nilai koefisien regresi sebesar 0.046 dengan tingkat signifikansi 0.005 yang artinya variabel ini memiliki pengaruh positif dan signifikan terhadap Komitmen Organisasi (Y) dengan tingkat kepercayaan sebesar $99 \%$.

Variabel Agreeableness (X2) memiliki nilai koefisien regresi sebesar 0.051 dengan tingkat signifikansi sebesar 0.006 yang artinya variabel ini memiliki pengaruh positif signifikan terhadap Komitmen Organisasi (Y) dengan tingkat kepercayaan sebesar $99 \%$.

Variabel Conscientiousness (X3) memiliki nilai koefisien regresi sebesar 0.055 dengan tingkat signifikansi sebesar 0.000 yang artinya variabel ini memiliki pengaruh positif signifikan terhadap Komitmen Organisasi (Y) dengan tingkat kepercayaan sebesar 99\%.

Variabel Conscientiousness (X4) memiliki nilai koefisien regresi sebesar 0.032 dengan tingkat signifikansi sebesar 0.001 yang artinya variabel ini memiliki pengaruh positif signifikan terhadap Komitmen Organisasi (Y) dengan tingkat kepercayaan sebesar 99\%.

Variabel Neuroticism (X5) memiliki nilai koefisien regresi sebesar 0.043 dengan tingkat signifikansi sebesar 0.002 yang artinya variabel ini memiliki pengaruh positif signifikan terhadap Komitmen Organisasi (Y) dengan tingkat kepercayaan sebesar $99 \%$.

Variabel Openness to Experience (X6) memiliki nilai koefisien regresi sebesar 0.045 dengan tingkat signifikansi sebesar 0.003 yang artinya variabel ini memiliki pengaruh positif signifikan terhadap Komitmen Organisasi (Y) dengan tingkat kepercayaan sebesar 99\%.Pimpinan kantor Dinas Kesehatan Prov. Sulsel sebagai memberikan pendelegasian tugas (job description) yang jelas pada masing-masing karyawannya. Ketidakjelasan job description tiap individu mengakibatkan tumpang tindih pekerjaan dan adanya pengangguran terselubung pada instansi tersebut.

\section{DAFTAR PUSTAKA}

Alwisol. (2005). Psikologi Kepribadian. Ed. Revisi. UMM Press : Malang

Ardana, I Komang, NiWayan, Mujiati, I Wayan Mudiartha Utama. (2012). Manajemen Sumber Daya Manusia. Graha Ilmu : Yogyakarta

Bangun, Wilson. (2012). Manajemen Sumber Daya Manusia. Erlangga : Jakarta

Budyatna, Muhammad dan Leila M.G. (2011). Teori Komunikasi Antar Pribadi. Kencana: Jakarta

Dessler, Gary. (2010). Manajemen Sumber Daya Manusia.Terjemahan oleh Paramita Rahayu. Jilid I Ed 10. Indeks : Jakarta Barat

Iriantara, Yosal. (2008). Komunikasi AntarPribadi. Ed. 2. Universitas Terbuka, Departemen Pendidikan Nasional : Jakarta

Ivancevich, John. Robert Konopaske dan Michael T Matteson. (2007). Perilaku dan Manajemen Organisasi. Terjemahan Oleh Gina Gania. Jilid I Ed 7. Erlangga : Jakarta

Jarvis, Matt. (2000). Teori-teori Psikologi : Pendekatan Modern untuk Memahami Perilaku, Perasaan, dan 
ISSN : 2339-1510

Pikiran Manusia. Terjemahan oleh SPA-Teamwork. 2007. Bandung : Nusamedia \& Nuansa

Luthans, Fred. (2006). Perilaku Organisasi. Terjemahan Oleh Vivin Andika Yuwono, Shekar Purwanti, Arie P, dan Winong Rosari. Ed 10. ANDI : Yogyakarta

Sugiyono. (2012). Metode Penelitian Kombinasi (Mixed Methods). Alfabeta : Bandung 